\title{
Understanding Smart and Automated Parking Technology
}

\author{
Prof. Yatin Jog, Anuja Sajeev ${ }^{1}$, Shreyas Vidwans ${ }^{2}$ and Chandradeep Mallick ${ }^{3}$ \\ ${ }^{1}$ Professor at Symbiosis Institute of Telecom Management \\ ${ }^{123}$ Student at Symbiosis Institute of Telecom Management \\ yjog@sitm.ac.in,anuja.sajeev@sitm.ac.in,shreyas.vidwans@sitm.ac.in, \\ chandradeep.mallick@sitm.ac.in
}

\begin{abstract}
The rapidly growing urban population of India is creating many problems for the cities, vehicle parking being one of the major problems faced almost every day. The number of vehicles is also increasing daily adding to the parking vows at public places. India has more than 40 million vehicles as of 2014. The traffic on roads and parking space has been an area of concern in majority of Indian cities.

To avoid these problems, recently many new technologies have been developed that help in solving the parking problems to a great extent. Multi-level car parking system (MLCPS) is one such technology which is implemented in India. It is used for optimum utilization of parking space by utilizing vertical space rather than horizontal space. Some of the benefits of MLCPS are optimum utilization of space, low construction cost, low working and maintenance cost to name a few. Although automated parking(Mathijssen \& Pretorius, 2005) [1] like multilevel parking has made the condition a little better than the earlier situation, there is still scope for improvement. This is because people still face problems of space availability, searching time and waiting time in public places like malls, multiplexes, railway stations, shopping streets etc. With the new technology of smart parking, majority of these issues will be solved.

Smart parking uses sensors, wireless communication technology, data analytics(Aggarwal, 2011) [2] etc. to solve parking issues. Smart parking solutions can be used to locate available parking space with the help of sensors. This saves customer's time as well as minimizes wastage of fuel. Various technologies are being used to ease parking problems in public places. For example using RFID technology, the check in and checkout time for the vehicle can be reduced and also the payment system can be automated. Similarly using wireless sensors information like parking duration, available slot, billing details, directional details etc. can be obtained which will help the drivers and will thus ease out parking vows. Using GSM, Short message service can also be used to provide drivers with relevant parking information. In another technology which uses QR code, the user can pre book the desired parking space which saves his searching time and also saves fuel. In automated multilevel car parking, the car is lifted and placed at the available slot. This is done with the help of robotics and a lot of software programming.
\end{abstract}

Keywords: Multi-level car parking system (MLCP), wireless communication technology, data analytics, RFID technology, Automated parking, GSM, QR Code, Robotics

\section{Introduction}

Smart parking is a niche field in which many companies are now investing heavily and the car parking industry has tremendous potential since the parking problems in developing and developed countries is increasing. Internet of things (KANG, 2011) [3] is the next internet revolution which is going to trigger machine to machine communication. 
Smart parking is a part of Internet of things wherein sensors will talk to remote devices over internet and share information using predefined communication protocols. This paper deals with the parking issues faced by people, their awareness about the new upcoming smart parking technology and their willingness to adapt to this new technology. Also, the paper throws light on some of the smart parking technologies currently used across the globe.

\section{Parking Issues in India}

India has more than 40 million vehicles. But the traffic on roads and parking space has been an area of concern in majority of Indian cities. In most of the cases, 40 per cent of the road space is used for parking rather than for traffic movement on a normal working day. With affordable cars launching in the market, almost every middle-class family owns a car which adds to the vehicular population in our country. If this trend is followed, no amount of space will be enough to accommodate stationary vehicles, which will lead to narrower lanes for movement of public transport.

The present situation in some areas of Indian cities is such that the demand for parking is twice the supply. Shortage of parking hinders the free flow of traffic and can also lead to accidents. It also causes air pollution, traffic jam and driver frustration. Some of the reasons for parking problems are:

- Low parking prices

- Weak implementation of parking regulations

- Number of vehicles is rising day by day

- The footpaths are not properly constructed so walking environment is not comfortable. Hence prosperous vehicle owners do not prefer parking their vehicles three or four meters away.

- Vehicle owners are not willing to pay the parking amount and often end up parking on the streets so building space for parking can seem like a waste.

So to avoid all these problems, researchers recently have turned to applying technologies for efficient parking management(Joshi, Khan, \& Motiwalla, 2012)[4]. These technologies have helped in solving the parking problems to a great extent. Different technologies are applied at different places according to the parking environment and the type of parking requirement in that area. The technologies used are as follows:

\section{Parking Solutions Already Prevalent in India}

It is used for optimum utilisation of parking space by utilizing vertical space rather than horizontal space. The growing population and the increase in vehicles have made the plots expensive and hence the conventional parking has become non-feasible. Car ramps or car lifts also consume a lot of space therefore mechanized car parking systems prove to be feasible.

Multi-level car parking system (MLCPS) has a number of advantages over the conventional parking system. Some of the advantages of MLCPS are stated below.

\subsection{Advantages:}

- Best use of Space

It uses pallets and lifts for parking and retrieving cars. Therefore it eliminates the need of drive ways and ramps. This leads to optimum utilisation of space.

- Low construction cost

Construction cost of MLCPS is very less. It is delivered and assembled on the site itself. The system is automatically operated hence the extra expense of parking such as structure building, security etc. are avoided. 
- Low working and maintenance cost

Since MLCPS are mechanical systems, it needs less energy for its operation. Ventilation systems which are used for underground parking is not needed in this case. Cladding is selected to match the building's frontage.

- Security of vehicle

The parked cars in MLCPS are safe and cannot be accessed by anyone else. Also damage to the car is avoided which usually happens when parking is done through narrow drive ways.

- Environment Friendly

The greatest benefit of MLCPS is saving the ground space which is wasted in the case of conventional space parking. The saved open space can be used to plant trees or make other buildings.

- Advantage to driver

Parking is made easier with MLCPS as the driver is not made to drive from the parking lot to find free parking space and do not have to park the car in the free parking lot(Sanngoen, Akihisa, \& Takashi, 2012) [5]. Even retrieving the car from the parking space does not require the driver. All this saves a lot of time.

- Benefit to architect

MLCPS can be used for both public and private use. It is designed to accommodate any number or cars. It makes difference in designing and planning places.

- Advantage to builder

MLCPS uses the area and the volume of the parking space more efficiently. This leads to more parking of cars in the same given space. This causes more financial gains by the builders.

\subsection{Limitations of MLCPS:}

- The vehicles of MLCPS on surrounding residential Blocks cause noise and air pollution.

- A pollutant such as motor oil leads to contamination of parking lots.

- The parking lot must be built in such a way that it effectively channel and collect runoff which would have otherwise become runoff.

\section{Types of other Parking Solution Currently Available}

\subsection{Conventional Multilevel Parking}

It can be above the ground, underground or both above and underground. The above ground structures are open-deck parking structures. The design of conventional MLCPS includes entry and exit ramps and/or car lifts between the vehicles and car parking area.

\subsection{Automated Multilevel Parking}

Technologies used for automated parking systems are of the following types:

- Puzzle Type or Modular

- Elevated Type or Tower

- Multi-Level Floor Parking

- Multi-Level Circulation Automated Parking System

- Rotary type

- D (Stacker) System 


\section{Automated Parking Systems: A Growing market in India}

Autopass India is a company working exclusively in car parking solutions in India. It provides $24 \times 7$ real time parking bay availability on large LED panels at the entrance, navigates the cars by the shortest route to the nearest available parking bay(Yu-Chi, Jyong, \& Shih-Chang, 2010) [6], helps the customers to reduce car movement by eliminating the need to find vacant spaces and helps the parking lot owner to manage the parking system efficiently by proving software generating important customer and utilization data.

Parking management involves two primary things. First is easy and hassle free entry for the customer along with easy parking space availability and easy exit and second is efficient parking management for the parking lot owner so that he can improve the experience for the customer.

Till the last decade, parking facilities in India were poor. Parking lots were not secure. There used to be a long queue at the entry and exit because of the manual systems. But with increasing economic conditions, people started looking for places which give better experience in parking. The natural places affected were malls, multiplexes because people started differentiated them in terms of the parking facility provided. So now malls, multiplexes, shopping complexes etc have understood the importance of providing better and better parking facilities in order to retain and increase their customer base. Thus the parking system market is growing in India and with the construction of new malls, airports etc automated parking systems and smart parking is gaining momentum.

Autopass India provides state of the art parking guidance system which helps drivers find the available parking from any location in the parking lot. The main advantage of Autopass India's parking guidance system is that it enables quick clearance of vehicles at the point of entry; traffic jams are avoided and thus gives a better overall parking experience.

\section{Smart Parking on the Rise}

Presently, worldwide cities are getting saturated in terms of space available. With construction of new buildings, parking space is getting diminished. So companies are now coming up with innovative solutions to the parking problem. Thus the car parking industry is facing the biggest growth currently. As per Navigant research the installed base of parking spaces on streets will exceed 950,000 worldwide by 2020 .

Since the horizontal space is getting saturated, the smart parking solutions are looking at vertical spacing that is say in the horizontal space if 2 cars can be parked then smart parking solutions aim at parking around 16 cars in the same horizontal space but in vertical fashion.

The main goal of smart parking solution is to enable both drivers and parking managers in optimizing parking capacity. Various technologies like in car sensors, wireless communications data analytics are being used. Also now innovation in smart phone apps have enhanced customer services since mobile payments can be made through the phone itself. Also, the apps can provide the customer with the real time data as to how many parking slots are currently available, which one is nearest to the customer's location etc.

\subsection{Example of a New Parking Solution that has Currently Emerged in Coimbatore}

Coimbatore has got its smart parking solution through a Korean company Dongyang which is a specialist in fully automated parking solutions and has provided smart parking solutions in many countries. Dongyang has partnered with Parklayer India and Procraft Automation has installed the Parklayer-Dongyang systems at Aquasub Engineering in Coimbatore. 
Now many cities are coming out with different solutions for car parking. In Coimbatore, hospitals, malls, multiplexes, commercial complexes are coming up with multilayer parking bays.

The smart parking management systems(Bandu, Dr. Ranjana, \& Dr. Pravin, 2014) [7] use rotary technology where in a single unit can hold upto 16 cars. It needs $16 \times 21$ feet land. The user has to select an empty bay. The bay will come down to the ground level. The user can park on that bay and again press the button; the bay will take the car to its position. Similarly, it can be brought down by pressing the number of the platform on which it is parked.

Smart parking concept is still new and the demand has to come mainly from the local bodies and commercial establishments like the malls, multiplexes etc. The need for smart parking is for more than two or three levels of car parking units.

\subsection{Smart Parking Systems would Reach Nearly \$360 Million in Annual Revenue by 2020}

A research estimates that the income from smart parking systems will reach $\$ 356.5$ million yearly by 2020 worldwide. Thus smart parking has a lot of potential and is going to experience tremendous growth in the coming years. With increasing parking demands, companies are coming up innovative and smart solutions to address these demands. Also the horizontal space constraints have prompted the innovators to venture in the vertical space. Creating more parking spaces is not going to solve the problem but we need a stable vision of parking that manages the association between supply and demand. Optimum use of the available space is what should be looked at. For example, in the parking space of 2 vehicles we should be able to park 10 or more vehicles effectively.

Smart parking will also benefit the cities. It will have positive impacts on the revenue system. It will help both the user as well as the provider that is the car parking owner. One area which can be looked at is the on-street parking (Mgidange, 2014) [8] which occupies lot of space. If we have multilevel bays on the streets in the same space double or triple number of cars can be parked thus achieving space optimisation.

\subsection{Companies Focusing on Lifts/ Elevators/ Traveletors can Tap Automated Car Parking Market in India in an Organised Manner}

Currently automated smart parking market in India is unorganised and faces lot of challenges like lack of regulatory body to control the quality of ACP systems, lack of skilled labour to assemble and high initial investment to name a few.

Since lifts/ elevators/ traveletors have the inherent technology they can extend it to design the automated car parking system which will gain them huge profits since currently Indian companies are procuring the systems from foreign companies and then installing it here. Also these companies can form a consortium and set standards and help quicken the automated parking system in India.

Smart Parking is gaining slowly gaining market in India. With lot of public private partnership infrastructure projects coming up, the parking industry has promises a good future. These projects involve construction of multilevel parking bays at various places in India and are encouraging smart parking industry to come up with innovative solutions. With Govt's plan of building 100 smart cities, smart transportation is pacing ahead with lot of companies, start-ups getting into these fields. We have companies exclusively providing smart parking solutions. The companies are Delopt, Skypark, Pristech, Autopass India, Global Technologies and many more. 


\section{Smart Parking Technologies Currently Available throughout the World}

Opting for a parking space in cities during the peak hours is an arduous job for daily commuters. The situation arises from people who are unaware of available spaces maybe at that time; even if known, many vehicles in the parking space cause serious traffic congestion.

Hence a good amount of time period is lost for searching an available space and also found that $80 \%$ more fuel wastage is done than normal to find a vacant parking space in parking area. To solve this problem, special system in the parking area to find empty space and show the information to the people who search for the empty space are designed.

\subsection{Smart Parking System using Wireless Sensor Networks}

One method uses sensors which are cost effective and they detect if a car is present or absent in particular parking space i.e. real-time parking space availability. Additionally, the sensors also give information like the car parking time and also the health status.

Besides displaying the availability status at various locations which has strategic importance, they also provide the information such as slot allocation, car park timing, and information about billing and directional assistance to the driver's mobile phone via SMS. The SMS feature is used because the number of mobile phone users is very large and the use of SMS also saves cost incurred in printing parking bills and thus saves paper too.

The smart parking system which uses sensors is highly energy efficient and cost effective as it uses only a single sensor. The use of adaptive algorithm is reliable and detects presence as well as absence of a car efficiently. Reservation of parking lot(Wang, 2011) [9] on real time basis can also be done.

\subsection{Smart Parking Applications using RFID Technology}

RFID is a well-known technology which provides wireless data transmission through wireless sensors(Urdiain, Romero, Doggen, Dams, \& Houtven, 2012) [10]. Although utility of RFID is known for a long time, it was not utilized to its full potential. Smart parking application which uses RFID technology requires no human intervention and is used for vehicle detection. It can also be used to develop automatic parking fee collection system. This technology helps the drivers to quickly check-in and checkout from the parking lot and also makes the parking secure. The RFID sensor at the entry point helps in avoiding multi check-ins thus avoiding traffic congestion in the parking lot. The RFID technology enables automatic parking fee collection thus saving time of the drivers. The main components of RFID technology that are used for the purpose are RFID labels, RFID readers, software system and a barrier to control the gate. The transaction management, reporting and operational tasks are controlled by the software used in RFID. A database management system is also used to manage and record the vehicle tracking data and is considered within software requirements.

\subsection{Car Parking System using GSM and RFID}

The main components which are used are microcontroller, RFID(PALA \& INAN, 2007) [11] module \& GSM module. The microcontroller is generally interfaced with GSM and RFID module. The GSM technology uses the SMS service to locate the available parking space in a parking lot. The IR sensor which is placed at that parking slot, examines if it is vacant, and if it finds that there is availability, then it sends a confirmation. The SMS contains details like the Parking slot number, allowed Parking period, the tariff for parking which is proportional to the time duration and a security code. 
The whole process starts with the user when he/she send an SMS to the GSM module which is fixed in the parking lot. After that, the GSM module sends the password and the available parking space number to the driver. Once it is sent, the counter for reservation time starts automatically. The driver then has to park the vehicle according to slot number that has been provided, taking help from the LED lights placed there. The green LED represents vacant slot. After the vehicle has been parked in the selected spot, the green LED is switches off automatically meaning that the slot has been occupied. The driver then has to use the password which is sent to him for making an entry and exit through the barrier gate. The RFID tag is generally used to authenticate the registered users.

\subsection{QR code based Vehicle Parking System}

In this model the important components are the parking zones, the users and the database required for the smart parking system. The management decides the parking tariffs and broadcasts live parking information to vehicle drivers. On receiving parking details, the user chooses a desired parking space and also books a space. Upon confirmation of the parking space, SPSR generates a unique QR code(Kieseberg et al., 2010)[12] and sends it to the user. As a result, users' parking decisions changes the state of parking resources. The reservation authority distinguishes each user by the unique $\mathrm{QR}$ code which the management system has sent to the user at the time of reservation. After the reservation is done, the management updates the data. Based on the state of parking lot, the system --

- Analyses the congestion level and vacancy status.

- Selects the parking prices depending on the pricing system.

- Periodically show the prices to all users.

- Stores the QR code, prices and parking information for future analysis.

The system with QR code(Shintaro, Hairong, \& Morikazu, 2012)[13] works as the central decision-making authority in an economy.

\subsection{Multi-level Car Parking System using Image Processing}

This technology which uses Image processing(M.O., M.F., A.A., \& M.A.R., 2012)[14] exercises automated car parking which transports cars to different parking levels. Hence, this car parking system requires less floor space area thus saving on the cost of building. In most cases, a circular parking system is found where the cars are being lifted from the base level. The base rotates circularly while a rack-pinion mechanism is used to lift the cars to the parking chamber at different levels. To lift and place the cars in an empty space is a tedious task and hence robotic arms or gripping mechanism is found in the parking systems.

\section{Smart Parking Potential in India}

We conducted a survey to understand the awareness of Smart Parking and its implementation within the population. First we tried to know about the issues that public generally faces during parking. We also tried to know where they face the issues the most. Then we tried to know if they are willing to adopt the new technology of smart parking. For collecting the data, we visited many public places like malls, shopping street, corporate office areas which majorly face parking issues. We prepared a survey questionnaire which contained around 20 questions and got it filled by the people. The sample population varied from male to female, student to corporate managers, teenager to aged people with varied income groups. Through this survey we also tried to educate the masses about Smart parking and also make them aware about the various benefits that they would derive from it.

The post analysis of the survey is done using SPSS and has been explained in the 
following sections.

\section{Analysis of Questionnaire}

\section{Hypothesis 1: People are Aware of Smart Parking}

Ho: $\mu<=2 \quad$ People are aware of smart parking

H1: $\mu>2 \quad$ People are not aware of smart parking

I am aware of smart parking

\begin{tabular}{|ll|r|}
\hline N & Valid & 104 \\
& Missing & 0 \\
Mean & & 2.9808 \\
Median & & 3.0000 \\
Mode & & 4.00 \\
\hline
\end{tabular}

I am aware of smart parking

\begin{tabular}{|c|c|c|c|c|c|}
\hline & & Frequency & Percent & Valid Percent & $\begin{array}{c}\text { Cumulative } \\
\text { Percent }\end{array}$ \\
\hline \multirow{6}{*}{ Valid } & Strongly Agree & 15 & 14.4 & 14.4 & 14.4 \\
\hline & Agree & 29 & 27.9 & 27.9 & 42.3 \\
\hline & Neutral & 16 & 15.4 & 15.4 & 57.7 \\
\hline & Disagree & 31 & 29.8 & 29.8 & 87.5 \\
\hline & Strongly disagree & 13 & 12.5 & 12.5 & 100.0 \\
\hline & Total & 104 & 100.0 & 100.0 & \\
\hline
\end{tabular}

\section{One-Sample Statistics}

\begin{tabular}{|l|r|r|r|r|}
\hline & \multicolumn{1}{|c|}{$\mathrm{N}$} & \multicolumn{1}{|c|}{ Mean } & Std. Deviation & Std. Error Mean \\
\hline i_am_aware_of_smart_parking & 104 & 2.6635 & 1.28177 & .12569 \\
\hline
\end{tabular}

\section{One-Sample Test}

\begin{tabular}{|l|r|r|r|r|r|r|}
\hline \multirow{2}{*}{} & \multicolumn{1}{|c|}{$\mathrm{t}$} & $\mathrm{df}$ & $\begin{array}{c}\text { Sig. (2- } \\
\text { tailed) }\end{array}$ & $\begin{array}{c}\text { Mean } \\
\text { Difference }\end{array}$ & \multicolumn{2}{|c|}{$\begin{array}{c}\text { 95\% Confidence } \\
\text { Interval of the } \\
\text { Difference }\end{array}$} \\
\cline { 2 - 7 } & & & & & Lower & Upper \\
\hline $\begin{array}{l}\text { i_am_aware_of_smart_- } \\
\text { parking }\end{array}$ & 5.279 & 103 & .000 & .66346 & .4142 & .9127 \\
\hline
\end{tabular}

Conclusion: From the frequency table we can see that around $43 \%$ of the people are not aware about smart parking. After running one sample T test, the significant value comes out to be zero which is less than 0.05 . Hence we reject the hypothesis. This implies that people are not aware about smart parking. 


\section{Hypothesis 2: People are adaptable to the new technology of smart parking} $\mu<=2$, people would like to adopt new technology.

$\mu>2$,people would not like to adopt new technology.

Here after removing the outliers, we have considered the responses of 97 respondents out of 104 to get proper output of correlation.

\section{Correlations}

\begin{tabular}{|c|c|c|c|}
\hline & & $\begin{array}{c}\text { i_consider_myself_a } \\
\text { s_tech_savvy }\end{array}$ & $\begin{array}{c}\text { i_would_like_to_adopt_new_tech } \\
\text { nology }\end{array}$ \\
\hline \multirow{3}{*}{$\begin{array}{l}\text { i_consider_myself_as_tech_ } \\
\text { savvy }\end{array}$} & Pearson Correlation & 1 & $.223^{x}$ \\
\hline & Sig. (2-tailed) & & .029 \\
\hline & & 97 & 96 \\
\hline \multirow{3}{*}{$\begin{array}{l}\text { i_would_like_to_adopt_new } \\
\text { _technology }\end{array}$} & rearson correlation & & 1 \\
\hline & Sig. (2-tailed) & .029 & \\
\hline & $\mathrm{N}$ & 96 & 96 \\
\hline
\end{tabular}

${ }^{\star}$. Correlation is significant at the 0.05 level (2-tailed).

Conclusion: Since we are comparing two variables we use the bivariate correlation. As we see the significant value $(0.029)$ is less than 0.05 , we accept the hypothesis. This implies that people would like to adopt the new technology of smart parking.

Hypothesis 3: Space Availability/ Searching Time/security concern is the main issue during parking

\begin{tabular}{|c|c|c|c|c|c|}
\hline \multicolumn{6}{|c|}{ What issue do you face the most while parking } \\
\hline & & Frequency & Percent & Valid Percent & $\begin{array}{l}\text { Cumulative } \\
\text { Percent }\end{array}$ \\
\hline \multirow{4}{*}{ Valid } & Space availability & 51 & 49.0 & 49.5 & 49.5 \\
\hline & Space searching time & 41 & 39.4 & 39.8 & 89.3 \\
\hline & Security concern & 11 & 10.6 & 10.7 & 100.0 \\
\hline & Total & 103 & 99.0 & 100.0 & \\
\hline Missing & System & 1 & 1.0 & & \\
\hline \multicolumn{2}{|l|}{ Total } & 104 & 100.0 & & \\
\hline
\end{tabular}




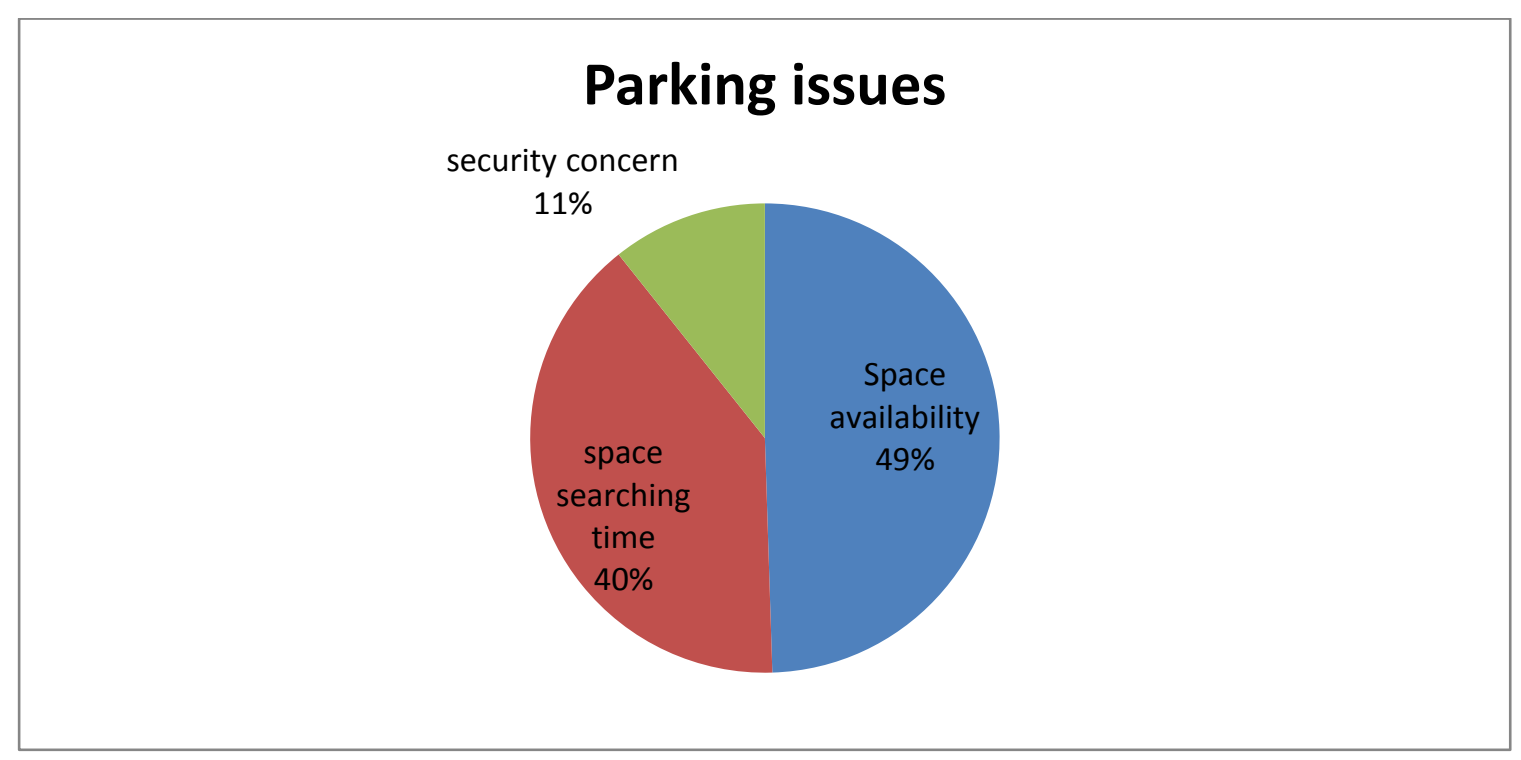

Conclusion: Almost half of the people face the problem of space availability while parking.

\section{Conclusion}

We can conclude from the survey that Smart Parking is at a very tender stage in India and people hardly know about the technology. They cannot distinguish between smart parking and automated parking which is already very prevalent in India. However people are willing to accept it as it will solve many problems like space availability, wastage of time, fuel and will also provide security to the vehicle. Hence Smart Parking has got a huge potential as many Smart City projects are coming up in India and a huge investment has already been lined up.

\section{References}

[1] A. Mathijssen and A. J. Pretorius, "Specification, Analysis and Verification of an Automated Parking Garage”, vol. 40, (2005).

[2] C. C. Aggarwal, "An Introduction to Social Network Data Analytics", DBLP, vol.16, (2011).

[3] H. Kang, "Design and Realization of Internet of Things Based on Embedded System Used in Intelligent Campus", International Journal of Advancements in Computing Technology(IJACT), olume3, pp. 298.

[4] P. Joshi, M. R. Khan and L. Motiwalla, Global Review of Parking Management Systems and Strategies, (2012).

[5] W. Sanngoen, O. Akihisa and T. Takashi, "Parking Place Inspection System Utilizing a Mobile Robot with a Laser Range Finder", (2012).

[6] S. Yu-Chi, L. Jyong and C. Shih-Chang, "A Study of Geographic Information System Combining with GPS and 3G for Parking Guidance and Information System", vol:4,no. 4, (2010), p. 7.

[7] N. Bandu, R. Ranjana and D. Pravin, "Performance Evaluation of Modern Sophisticated Parking Management System with Space Modeling”, International Journal of Innovative Research in Computer and Communication Engineering, vol. 2,no. 11, (2014), p. 8.

[8] V. Mgidange, Improving Efficiency of Parking Manitoring Systems in YVÄSKYLÄ Finland, (2014).

[9] H. Wang, (2011), "A Reservation-based Smart Parking System", University of Nebraska-Lincoln, Computer Science and Engineering: Theses, Dissertations, and Student Research, vol. 62.

[10] Urdiain, L. O., Romero, C. P., Doggen, J., Dams, T., \& Houtven, P. V. (2012). Wireless Sensor Network Protocol for Smart Parking Application Experimental Study on the Arduino Platform, 4.

[11] Z. Pala and N. Inan, "Smart Parking Applications Using RFID Technology", vol. 3, (2007).

[12] P. Kieseberg, M. Leithner, M. Mulazzani, L. Munroe, S. Schrittwieser, M. Sinha and E. Weippl, QR Code Security,vol. 6, (2010).

[13] O. Shintaro, L. Hairong and H. Morikazu, "Benchmarking the Use of QR Code in Mobile Promotion", Journal of Advertiding Research, vol. 17, (2012).

[14] M.O., R., M.F., I., A.A., R., \& M.A.R., S, "Smart Parking System with Image Processing Facility", MECS, vol. 47, (2012). 
[15] http://www.joneslanglasalleblog.com/realestatecompass/real-estate/2014/06/managing-parking-issuesautomated-parking-solutions/

[16] http://www.thehindu.com/todays-paper/tp-features/tp-propertyplus/parking-problems-in-spaceage/article4176733.ece

[17] http://www.engineeringcivil.com/different-types-of-parking-spaces-and-multiple-level-car-parking.html

[18] http://www.trafficinfratech.com/automated_parking_systems/

[19] http://smartcitiescouncil.com/article/smart-parking-rise-1-million-spaces-2020

[20] http://www.thehindu.com/news/cities/Delhi/delhi-gets-south-square-first-automated-multilevelparking/article2614888.ece

[21] http://www.thehindu.com/todays-paper/tp-features/tp-propertyplus/level-up/article4983151.ece

[22] http://www.fastprk.com/our-solution/what-is-fastprk.html

[23] http://www.navigantresearch.com/newsroom/smart-parking-systems-will-reach-nearly-360-million-inannual-revenue-by-2020

[24] http://uk.reuters.com/article/2014/04/08/research-and-markets-idUKnBw086053a+100+BSW20140408

[25] http://www.researchandmarkets.com/research/g5tltp/smart

[26] http://www.frost.com/prod/servlet/press-release.pag?docid=218340652

[27] http://deshgujarat.com/2014/09/07/china-to-set-up-industrial-park-cum-smart-city-at-sanand/

[28] http://www.policychargingcontrol.com/services-innovations/2548-cisco-smart-city-to-drive-iot-and-ioeinitiatives-in-india-accelerates-realization-of-digital-india

[29] http://chimalaya.org/2014/07/05/india-expects-100-new-smart-cities/

[30] http://www.infotechlead.com/2014/09/23/cisco-smart-city-sets-blueprint-for-future-communities-inindia-25478

[31] http://indiatransportportal.com/2012/01/our-experience-on-parking-management-can-help-to-achieve-abetter-fluidity-of-the-traffic-s-sundar-ceo-smart-parking-india/

[32] http://www.parking-net.com/parking-industry/hectronic-india-retail-parking-automation-pvt-ltd

[33] http://www.parking-net.com/parking-news/search?q=india

[34] http://www.ndtv.com/article/cities/mumbai-high-tech-system-to-park-16-cars-in-2-slots-123451

[35] http://cse.unl.edu/ byrav/INFOCOM2011/workshops/papers/p701-wang.pdf

[36] http://ijret.org/Volumes/V03/I02/IJRET_110302042.pdf

[37] https://www.thinkmind.org/download.php?articleid=sensorcomm_2012_13_10_10291

[38] http://rfidlab.iecs.fcu.edu.tw/RFID/Papers/M0157204-2.pdf

[39] http://www.ijsrp.org/research-paper-1012/ijsrp-p1007.pdf

[40] http://www.ijera.com/papers/Vol3_issue5/CM35495498.pdf

\section{Authors}

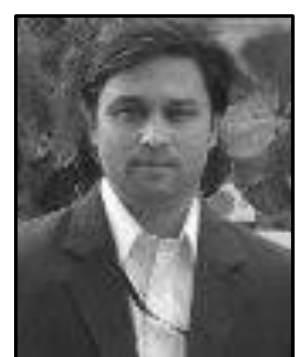

Prof. Yatin Jog is a faculty at Symbiosis Institute of Telecom Management, Pune and teaches IT, Telecom, Statistics and Networking subjects. He has obtained his MSc degree in Computer Science from Ahmednagar College (2003-2005) and MCM from Wadia College (2001-2003). His certifications include Business Process Framework (eTOM) Level 2, ITIL Foundation V3, ISO 27001 Lead Auditor and ISO 22301 Implementer

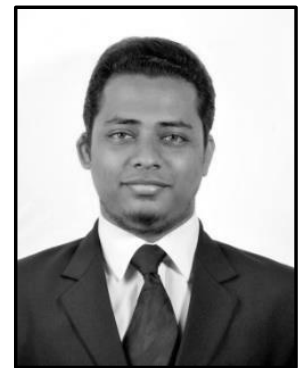

Shreyas Jayprakash Vidwans is currently pursuing MBA in Telecom Management with specialization in Marketing and Finance from Symbiosis Institute of Telecom Management, Pune. Prior to this he has 26 months (2011-2013) of Work experience in Larsen \& Toubro Limited in Business Development and Marketing department. His area of interests includes Wireless Technologies, Brand Management, Customer Relationship Management. His certifications include ITIL V3 Foundation, BCMS Implementation ISO 22301:2012. He completed his BE Electronics from Mumbai University in 2011. 

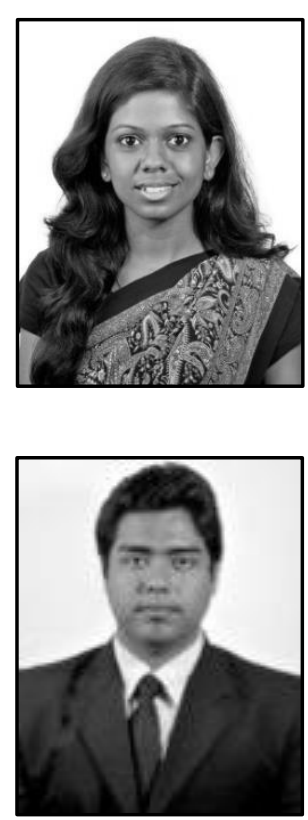

Anuja Sajeev is currently pursuing MBA in Telecom Management with specialization in Systems and Finance from Symbiosis Institute of Telecom Management, Pune. She has completed her BE in Electronics and Communication from Gujarat Technological University in 2014.Her area of interests includes telecom trends and marketing. Her certifications include ITIL V3 Foundation, BCMS Implementation ISO 22301:2012.

Chandradeep Mallick is currently pursuing MBA in Telecom Management with specialization in Marketing and Finance from Symbiosis Institute of Telecom Management, Pune. Prior to this he has 29 months of Work experience in Wipro Technologies Limited in Software development. His area of interests includes Business Development, Strategic Management Wireless Technologies. His certifications include ITIL V3 Foundation, BCMS Implementation ISO 22301:2012. He completed his Btech in Biotechnology from SRM University in 2011. 